these gaps. Different stakeholders (including universities, Project Management firms, and HEC), to improve the standard of Project Management education in Pakistan, can use our findings. University administration tries to mitigate the gap between practice of Project Management in the market and class theory while HEC should work on standardisation and management of Project Management education across different universities of Pakistan.

Demand of project management is developing significantly in labour market, which boost the progressing around project management education and training (Price M, 2004; Thomas, 2004). Many professional organizations around the world enhancing certification processes and Project Management Standards to improve the skills of the project managers in the practical market of the world.

In the current era projects play a very important role in the endeavours of growing number of businesses, developing programmes, venture based framework is supplementing or in any event, substituting customary useful. Project Management establishment as specified by the (PMI, 2013), according to the research in approximately range of, 18.5 million of projects management new job will be advertised in between 2010 and 2020. Along with demand of the project-based organizations, importance of project industries are facing problems and challenges in implementation of projects and failure of the project rate is increasing. The expected performance of the project management office, group of project managers and project management practitioner is overcome than the actual ground performance. (Hammoud, 2008; Jergeas, 2008; Jergeas and Ruwanpura, 2009; Pomfret, 2008; Stanley and Uden,2013; Tabernik, 2009). There are many example in mentioned in the Chaos report of 2009, $68 \%$ of the projects end while failing, impact and outcome of the project is not as were expected (Johnson, 2009). According to the researchers and experts to overcome the challenges of managing project in the market, new and efficient approaches needed to developed to fulfil need of the market demand (Atkinson, 2008; Córdoba and Piki, 2012; Winter et al., 2006).

Besides, disappointments to design precisely and control inside "adequate" restrictions are ordinary, and projects fall flat at an amazing rate regardless of the expanding enthusiasm for project management and project management usage throughout the most recent decades (Morris PWG, 1991; Flyvbjerg B, 2003; H Kerzner - 2019 ), actually, there is practically no exact proof that prepared as well as confirmed project chiefs more fruitful from "coincidental" project directors in the present complex world.

Simultaneously, the job intricacy, turmoil, and powerlessness play interior our projects and venture circumstances are picking up affirmation in both inquire about and hone. From now on, the time has come to review our comprehension of project management training and reflect about how we create project supervisors. Specifically, we have to talk about new points of view and ideas (Thomas, J., \& Mengel, T,2008). For a propelled degree of project management instruction that may build up the capacities important to explore with certainty inside the dynamic hierarchical conditions and complex projects confronting project supervisors today.

In this paper main objective is to look at the present project management status to instructive practices to contrast them with the structure squares of innovative project management training that prepares for complex conditions. The vast greater part of suppliers and projects in North America appear to concentrate on the Project Management Book of Knowledge (PMBOK) Foundation (PMI, 2004) founded exchange of "realize know who and what" planned for betterment the critical thinking aptitudes in the project management from project management experts. In Europe, the attention is on preparing to the gauges gave by proficient affiliations, for example, the APM or on benchmarks 
acknowledged by significant project proprietors. Many of students fight as others have as of late that this degree of instruction neglects to get ready project management understudies management of the expanding unpredictability in which they face in the present labour market nor does it utilize existing creative learning situations and methods.

Next, we take a gander at the effect of taking ideas of unpredictability and multifaceted nature hypothesis genuinely on project management and project management instruction. Specifically, exhibit how profoundly versatile and responsive frameworks with an enormous number of autonomous yet communicating specialists for new initiative methodologies outside the ability to control the room of representative of training of project managers in the sympathetic and imaginative assistance of progress. We additionally investigate late project management writing that talks about what aptitudes and capabilities project administrators should be effective in a world that pays attention to multifaceted nature.

Moreover, we examine the necessities for a propelled degree of project management training that plans project directors to manage multifaceted nature. In view of the three project management knowledge dimensional, they recommend an increasingly extensive methodology towards the improvement of the "genuinely and profoundly insightful" project pioneers associated with exceptionally perplexing and one of a kind projects. Specifically, in talking about how building up the ace project chief may go past the present spotlight on the exchange of section level knowledge and on the preparation of fundamental critical thinking aptitudes inside customary learning conditions, we expand on prior proposals for innovative project management training.

At long last, we investigate open doors for electronic instruction at the expert level by taking a gander at how this specific learning condition is helpful for building up the particular aptitudes expected of senior project directors working in a mind boggling condition.

The "Project Management Competency Improvement Structure" distinguishes a somewhat extensive rundown of knowledge and execution markers including individual capabilities pivotal for project management accomplishment notwithstanding the utilization of project management knowledge (Crosby, P. 2012). , p. 57]. In any case, these broader "shopping list" ways to deal with distinguishing project management abilities do not address the issues regarding the advancement or learning to how these aptitudes, capabilities and attributes are to be procured, when and what level or for which sort of the project. In the current project chiefs are left to pick in between these rundowns dependent on their possess best judgment.

Luckily, the absence of accessible course hours simply challenges, however, doesn't stop committing scholastics. Rather, overview respondents report that when they can't actualize a committed PM course they add PM substance to different courses.

\section{Project Management in Pakistan}

In early 1948 Economic Affairs Division (EAD) was established by the government of Pakistan. Despite financial problems and grave economic condition which beset, and to deal with all the development projects of the country. Six-year project development plan were initiated by EAD in 1950 and in Colombo Plans alive for Supportive Financial Development in the Asia of South and South East. It 
was basically a layout arrange and portrayed as it were a wide design of improvement.1 Government of Pakistan policy in the project management is to utilize natural and economic resource of the country efficiently for socio-economic welfare of the people. Importance of training and development in Pakistan has grown phenomenally, as civil service in Pakistan suffers from inadequate skills, low salary and deficient incentives, politicization, poor morale, and lack of internal or external accountability. These factors have resulted in ineffective delivery of public services in the country (World Bank, 2 oo1).

Several studies have highlighted the need of capacity building and training in project management system in Pakistan. World Bank (2006, p. 7) and Japan International Cooperation Agency [JICA] (2003) have emphasized upon the need for strengthening the project implementation capacity in Pakistan. While recognizing this problem in Pakistan, International Development Centre of Japan [IDCJ] (2004, p. 11) has highlighted the need for strengthening institutional implementation capacity so as to avoid any failure like that of Social Action Programme (SAP). SAP projects (SAP I commenced in 1994 and SAP II in 1998, each with cost of US\$250 Million) are examples of the worst failures in the country (World Bank, 2006, pp. 16 - 18). Sahibzada and Mahmood (1992) have also stressed on the need of up gradation of human skills of the public sector managers in Pakistan. They report that most of the government officials have never attended training, while others need refresher courses. It is evident that high rate of projects failure in Pakistan is associated with weak implementation capacity of the project organizations. Development of human capital in project organizations is imperative to improve the implementation capacity in a bid to reduce the incidence of project failure in the country.

In Pakistan none of university offering PhD in Project Management, students want to engage in project management, but due to lack of offering by university and high fees of project management Ms programs only $4 \%$ of the current enrolled students of Khyber Pakhtunkhwa want to do project management as a specialization (Ullah and Shah (2018; Arain, (2009).).

\section{Methodology}

\subsection{Questions:}

This study aims to answer the following question: What are the problems in the current project management education system of Pakistan? What difficulties are facing by project management professionals face presently in Pakistan? What are the suggestions about for future improvements in the project management education system of Pakistan?

\subsection{Respondents}

The population of the study consist of universities' graduates from Pakistan having bachelor or master degrees in management sciences of project management such as: Bachelor of Business Administration (BBA); Master of public Administration (MPA), Master of Commerce (M.Com) Master of Business Administration (MBA); or any relevant degree.2 Due to the lack of accessibility, fifty interviews were conducted within the vicinity of only one of the four provinces of Pakistan i.e., Khyber Pakhtunkhwa (KP); however, the graduates may have education experience across Pakistan. The total number of respondents is fifty, in which seven are female and forty-three male. An alumnus of the university is the principle reasons in project management programs, which have been popular in a wide (or MS) has eighteen years of education. 
range of enterprises. The recent published study by Ullah and Shah (2018) showed that only 8 percent female students opted for project management as their preferred career. There is diversity among respondents in order to have a good representative of the population.

\begin{tabular}{|c|l|l|l|}
\hline Characteristics & Value & Frequency & Percentage \\
\hline \multirow{4}{*}{ Gender } & Male & 46 & 92 \\
\cline { 2 - 4 } & Female & 4 & 8 \\
\hline \multirow{4}{*}{ Education } & MS & 9 & 18 \\
\cline { 2 - 4 } & Master & 37 & 74 \\
\cline { 2 - 4 } & Bachelor & 4 & 8 \\
\hline \multirow{5}{*}{ Age Group } & $25-35$ & 13 & 26 \\
\cline { 2 - 4 } & $36-45$ & 31 & 62 \\
\cline { 2 - 4 } & $46-55$ & 6 & 12 \\
\hline \multirow{5}{*}{ Years of Experience } & $1-5$ & 11 & 22 \\
\cline { 2 - 4 } & $6-10$ & 15 & 30 \\
\cline { 2 - 4 } & $11-15$ & 8 & 16 \\
\cline { 2 - 4 } & $16-20$ & 9 & 18 \\
\cline { 2 - 4 } & $20-25$ & 4 & 8 \\
\cline { 2 - 4 } & $26-30$ & 3 & \\
\hline
\end{tabular}

\subsection{Analysis}

The study is qualitative in nature. Semi-structured interview is chosen as a method of data collection because the research needs detailed discussion with the professionals (Khan, Burton and Power, 2011, Ullah and Khan 2018). The interviews are analysed using thematic analysis method of Braun \& Clarke (2006). Under the method, six-step framework is used i.e., familiarization with data, generation of initial codes, searching for themes amongst codes, review themes, define themes, and write up. It is important to mention that these six steps are not linear, and one can move forward and back (Maguire \& Delahunt, 2017). Within the domain of thematic analysis, the research adopts inductive approach instead of theoretical/deductive thematic analysis. We opt for inductive approach as this research focuses on the "process of coding the data without trying to fit it into a pre-existing coding frame, or the researcher's analytic preconceptions" (Braun \& Clarke, 2006, p. 12).

\section{Findings}

The answer of one project manager was different from the project manager of another organization. Due to the diverse nature of project management processes, a university is supposed to cater the needs of all graduates. However, it is not possible to do so, hence universities provide general, and basic project management case studies during classes, which makes it difficult for a project manager to enter in the practical market.

According to the Interviewee M9 said that; 
"Yes, it was. Actually, development sector has its own network. They do not let anybody else come into that network unless they have some kind of deficiency in a particular area, or if their partners are not fulfilling their requirements so if they are comfortable with their existing partners they do not let you into their network. The reason being that they are comfortable working with their existing partner who has the potential and capability. They also have known donors... the requirements of those donors. So, yes, it is difficult to get in to that."

For example, Interviewee M2 narrated that;

"Yes, I have faced the problems in the beginning because of lack of vacancies in the market at that time. Jobs were not easily available when I was a fresh graduate and with no experience. For almost one year, I kept on searching for the job. Another problem was that there is a big difference between public and private sector, at that time there was only public sector in the market therefore, you could just apply for the public sector. I have found my job after a lot of struggle and facing different problems.”

Interviewee M41 narrated that;

"The problems were merit issues, limited posts of project management and unemployment. The reason that I faced problems was that many fresh graduate candidates were available in the market and the available opportunities were very few. Therefore, saturation of job market was my biggest issue. I worked in different places where salaries were too low, but I accepted it because I needed experience to get eligible for a better job.”

Interviewee Mo4 narrated that;

“There were many problems, but I think the problems like weak links between universities and markets, lack of strong communication and interpersonal skills and above lack of awareness about the job market requirements."

\subsection{Problems Project Management Professionals Face}

After detailed analysis of 50 interviews, three main problems were identified which are faced by graduates (or project management professionals), i.e., deficiency of skills; limited no. of projects, short duration of projects, experienced project manager, but with a deficiency of theoretical knowledge, the gap between theory and practice; and non-completion of project courses. Many studied conducted in different countries to identify the gap between market demand and education system. Three main factors identified (i) "lack of critical thinking for dealing with complexity, (ii) developing softer parameters of managing projects especially interpersonal skills as opposed to just technical skills, and (iii) preparing project managers to be engaged within the context of real life projects Ramazani and Jergeas (2015).”

\subsubsection{Deficiency of skills}

We noted different answers in response to the first question are, while entering to the market what kind of problems which you faced regarding project management practices? About 44\% of respondents mentioned that the basic problem is lack of project identification and good implementation skills; $22 \%$ interviewees said that organizing and management are important skills; $12 \%$ reported that monitoring \& Evaluation skill is the main problem while 14\% noted that improper project closing and report writing as the main problem. 
In the development sector, a project manager M17 asserted that:

"Many fresh graduates facing different kinds of problem in the development sector, as its system is different from all other industries. Main problem is to identify the structure and culture of the organization, because here you have to work on data and generate fruitful information. Majority of the data and system are dong through different analysis applications, which needs practice, and you have to have background knowledge of that software's. The familiarity with the development sector, which the new graduates lack. The new employees are unable to identify the project in management structure in the organization and convey or transfer their knowledge in a good way in order to familiar with the environment.”

As study in the training and education of project management mentioned that "learning and development which facilitates the development of reflective practitioners who can learn, operate and adapt effectively in complex project environments." (Winter et al., 2006).

The skill deficiency intensified the resistance from the senior management, as they are unable to cope with the new technological changes. In this regard, interviewee M19 stated that:

"With due respect, the senior Project managers are still on jobs and they do not know anything about the latest technological gadgets and computer software's, to analysis the data special in the public sector. Training should give to the entire development sectors employee special in public sector."

\subsubsection{Gap between theory and practice}

In response to the 'gap between project management education and market demand', more than half of the interviewees agreed that universities management do not have that information which is the current market demand. These respondents documented that all contents of project management are not applicable in our field. They elaborated that there is a huge gap between the academic and practical project management needs. "That newly trained project manager was often unprepared for the complexity of managing projects. They believed that the challenge of how projects can be better managed in complex situations should be brought into the educational domain. The competency to work in increasingly dynamic and complex environments should be developed during the education of project management students. It can reduce the complexity shocks and surprises when they take charge as future managers Ramazani and Jergeas (2015).”

One of the issues is the limited information of market demand by the education sector. For example, Interviewee M23 mentioned that;

"The Universities management are not synchronized and not aware about the new technological recent trends of labour market demand. We do not have proper updated curriculum courses. They are teaching the same old syllabus since the project management course updated in 1990. The university management and teachers don't know how to adapt to the recent changes in project management course around the globe."

In response of the same question Interviewee M31 mentioned; 
"The overall education system is wrong in a sense that we are getting specialisation in one field (e.g., Human Resource, or economics) and doing work in another field (e.g., development). For one project manager-position all MA, Statistics, MPA, BBA, economics and science degree-holders are eligible, which arises many questions that how the student of Statistics, Economics, science, MA or MBA with diverse specializations can control the system of project management? There is no proper system to synchronize specialized education with project management profession in Pakistan.”

One experienced director mentioned:

"Yes, the issue of gap between market and the teachings in universities is still there. Sometimes when I go out people ask me about a particular experience and a particular education, but that education and particular experience is not acquired by me because those particular experiences were not involved in my study and then it becomes a problem".

Monitoring and Evaluation is also a basic component of project life cycle and in which we have lack of expertise in the market:

According to one M19: experts in M\&E reports"

"Monitoring and evaluation is one aspect of project management as well. We do not have enough people working in monitoring and evaluation part. Yes there are people who have experience in working in that sector but as far as degree or certification is concerned, these is no such certification of monitoring and evaluation in this field. In addition to this there are assessment requirement of projects, which people usually lack, then there is another aspect of project management which lacks a lot in terms of human resource and that is communication part. There are not many people who are good in report writing, plus there are not enough people who are good in producing statistical results for that matter so these are some of the areas that need to be focused for future students.”

\subsubsection{Role of HEC:}

According to majority respondents, the important factor behind the gap is the passive role of Higher Education Commission (HEC) of Pakistan. They asserted that HEC3 should intervene to update the project management curriculum at universities and do proper monitoring. As stated by Interviewee M29;

"I don't think there is any ahhhh any blame could be put to a specific area; we should come up with new areas of revenues that we think are in demand in the market and once we come up with those courses I don't think HEC will be having any such problem in recognizing that. By expertise, I mean project management for example is not a kind of a work that is degree dependent for that matter. If there are people who are working in the development sector having in some cases twenty years' experience of particular field they can design their own courses. Then there are people who have done these certifications or degrees on their own from abroad, most of them. So, we can take help of those people as well."

In addition, some of the respondents consider the 'contents' of project management modules is not

3 It is important to note that HEC is the only regulatory and advisory body for higher education in Pakistan. However, HEC cannot do micro-management during implementation of certain rules, as universities are autonomous in Pakistan. The HEC has developed complete course contents, but universities are legally not bound to comply. However, it is observed that universities do follow the instructions in order to get brownie points during annual ranking. 
updated. For example, Interviewee M28 noted:

"Everything is changing very rapidly in the technology world which bring affect in the environment of the organization; however, universities still teach the same old edition of project management cycle and manual which does not incorporate with the recent updates in Project Management education. New course content updated books (latest version) should be introduced and training to the project managers teachers recording new project management technology which can overcome the problem of fresh graduates in the labour market."

While one construction project director mentioned:

"First factor I will blame is the "University Management" because in two to five years the student is not skilled enough to overcome the practical way of dealing the project. In my view, the student should be able to overcome the barriers when he studies for 5 years. The second main reason according to me is "HEC," that HEC is not providing those subjects to universities which universities can teach them practically. Therefore, the main reason I blame is HEC and the University Management. They both have to sit down and make solution for this matter that can benefit the students in future."

Some of the respondents highlighted the issue of supply and demand in project management field of Pakistan. For example, Interviewee M28 stated;

"I don't think any blame can be put on a specific area; it is more about demand and supply kind of a thing. If there is no demand students will not go there and HEC will not produce those kinds of degrees. It's all demand and supply kind of a thing. There is demand but somehow there is not a lot of concentration or inclination towards those degrees. As a faculty member we should come up with new areas of revenues that we think are in demand in the market and once we come up with those courses I do not think HEC will be having any problem in recognizing those degrees. It's just you need a capable faculty with the required expertise to teach the course".

While another expert reported:

“I don't think I can click any one of them it's very simple we need to go to job market, have to see what their needs are? Their needs should be incorporated in course curriculum very simple. I mean HEC is there to manage the universities, I believe the out-dated curriculum is problematic, if we know what market demands are. we have to incorporate it in our course. So, I think it is curriculum which is important."

A handful amount of interviewees documented that 'amendment in the curriculum can reduce the gap between market demand and theory.

\subsection{Suggestions for Improvements}

\subsubsection{Suggestions Regarding Skills Deficiency}

As highlighted in the beginning that the most important problem project managers, sectors and staff are facing nowadays is the planning and implementation, majority respondents suggest improvement of this phase. Interviewee M1 from the development sector mentioned that; 
"Skill requirement to the professional labour market varies with the duration of their service, but main skills which are required are: Have to technical and analytical skills, can collect data from the field, and know about data analysis of the software's e.g. Excel, SPSS, CSPRo and R etc. Data interpretations very important for the project manager to present the data in such way which give fruitful result and understandable. To be in this competitive market you have to have both theoretical and practical background as then it will be much better."

\subsubsection{Suggestions for fixing the gap between theory and practice}

A thorough analysis of respondents' interviews following the suggestions is documented to lessen the difference between theory and Project Management practices.

\subsubsection{Curriculum revision}

To overcome the difference between theory and practical, 38\% respondents noted that the revision of curriculum can overcome the gap between project management education and practical work, as Interviewee M17 mentioned that;

"A large proportion of respondents suggested for the improvement of curriculum of project management to overcome these problems. As narrated by Interviewee M32;

"Yeah sure, but again by just copy pasting curriculum from Google will not help. You need to have faculty who have the expertise of that particular subject and know about the market demand. It is very easy for anybody to just go on Google and search for project management curriculum, but do we have people who can teach those subjects? This is the real problem, this is the question that if you have manpower and you have people who can raise their hands that yes I can teach, then yes curriculum needs to be required, but for me putting curriculum before the man power is just like putting a cart before the horse. Therefore, it is more of that kind. Therefore, we need to have a labour here. We have to identify the manpower and then ask those people to develop curriculum accordingly."

One other respondent M33 added that;

"The universities should include some related subjects in the Project Management curriculum to broaden the vision of students. There should be related subjects about political, legal, economic, and social aspects of Project Management education as taught in different parts of the world.”

\subsubsection{Writing skill, Analysis and student's interest}

Many respondents highlighted report writing, analysis and student's interest as an important factor. In the view of Interviewee M27 "Project management, as my experience tells me that you need to be good at planning, organizing, implementing, controlling and closing. You have to have skills of writing, analysing data, monitoring and evaluation and implementation of policies of projects for that matter. Soft skills play vital role in the organizations. These are the skills, but these skills are very difficult to be taught, it has come with experience. Students interest is important, because senior or teacher teach him how to swim, student have to go and have to swim to learn. This is something that students need to take initiative."

\subsubsection{Trainings and workshops}


A significant number of experts mentioned that teacher trainings could reduce the differences between market demands and Project Management education; as Interviewee M45 believes that;

"The most important factor / initiate is to train project management teacher, because they only know the curriculum that they had studied when they were student. They are currently not in touch with the professional market so they do not know about the current situation of the labour market. Through trainings, teachers would be able to relate the current requirements of the job market to their Project Management curriculum.”

Furthermore, many experts advised that workshop and seminar regarding market demand of project management can help students to know the market demand. As Interviewee M43 mentioned;

"If the HEC and universities' management arrange seminars and workshops to address the demand of the current market and practical aspects of Project Management education. So, the students will have idea about practical work while working in the practical market.”

\subsubsection{Summary:}

During the meetings, project administrators communicated assessments about the reasons for gaps among expected and real execution of project directors and discussed potential approaches to moderate them. They referenced the job of individual qualities, for example, character, capacities and inspiration in overseeing projects and furthermore the noteworthy job of preparing and instruction, which was the focal point of our investigation. is a rundown of what they accepted to be vital for a capable project chief: As a common sense issue, most said that in the wake of choosing the ideal people to oversee projects, a portion of the gaps could be filled or generally moderated during the instruction and persistent preparing process. They clarified that cutting edge project management always manages multifaceted nature, vulnerability, and ceaseless innovative and hierarchical change. This investigation conclude that graduates of project management need to have solid basic reasoning a development sector abilities, for example, correspondence and group working aptitudes; however the way things are, they don't have the essential competency in these fields.

Albeit, conventional project management training has exceeded expectations in giving a broad knowledge base to students, this paper talks about the need to go past that. In view of the experience of working project directors in this examination, in numerous territories of project management instruction and corporate preparing, the customary strategy for addressing is not constantly adequate or proper. We asked our interviewees and centre gathering boards about their courses I project management, the strategy for conveyance and how much they found those courses helpful. They clarified that the prevailing strategy for project management instruction and preparing they encountered were addressing. This is a reality, in light of the fact that in a dominant part of instructive establishments, the substance for quite a bit of project management necessities is conveyed through conventional talks, paying little mind to its ineffectualness (Ferraro, 2012; Rynes and Bartunek, 2013).

Understudy focused learning helps project management training go past detached strategies for instruction and joins dynamic ones, for example, project-based figuring out how to create basic reasoning, critical thinking, and synergistic learning. To urge students to create adaptable knowledge and characteristically inspire them to learn, the instructional framework should likewise insert learning in the settings that require the utilization of these learnings.

Project management training must get ready students to be versatile, astute, and ready to perceive the important changes. So as to do as such, contingent on the substance and setting of 
learning, the instruction and preparing strategies must pick the fitting procedure: to be instructor focused (addressing), or understudy focused (assistance, contextual analyses, project based learning, job demonstrating, reproduction,...) or a blend of these two. Project management students ought to likewise be urged to begin a learning procedure that will proceed for the span of their expert levels. From the point of view of the experts in our investigation, employees in project management instructive foundations ought to have down to earth understanding to have the option to satisfactorily relate hypothesis to common sense. The accompanying abilities are significant for best project administrator: Specialized aptitudes and abilities, good communication skills, data analysis and interpretation, good writing skills, Critical thinking abilities, Group Working, Arranging, evaluating/planning abilities and familiar with the analysis computer applications.

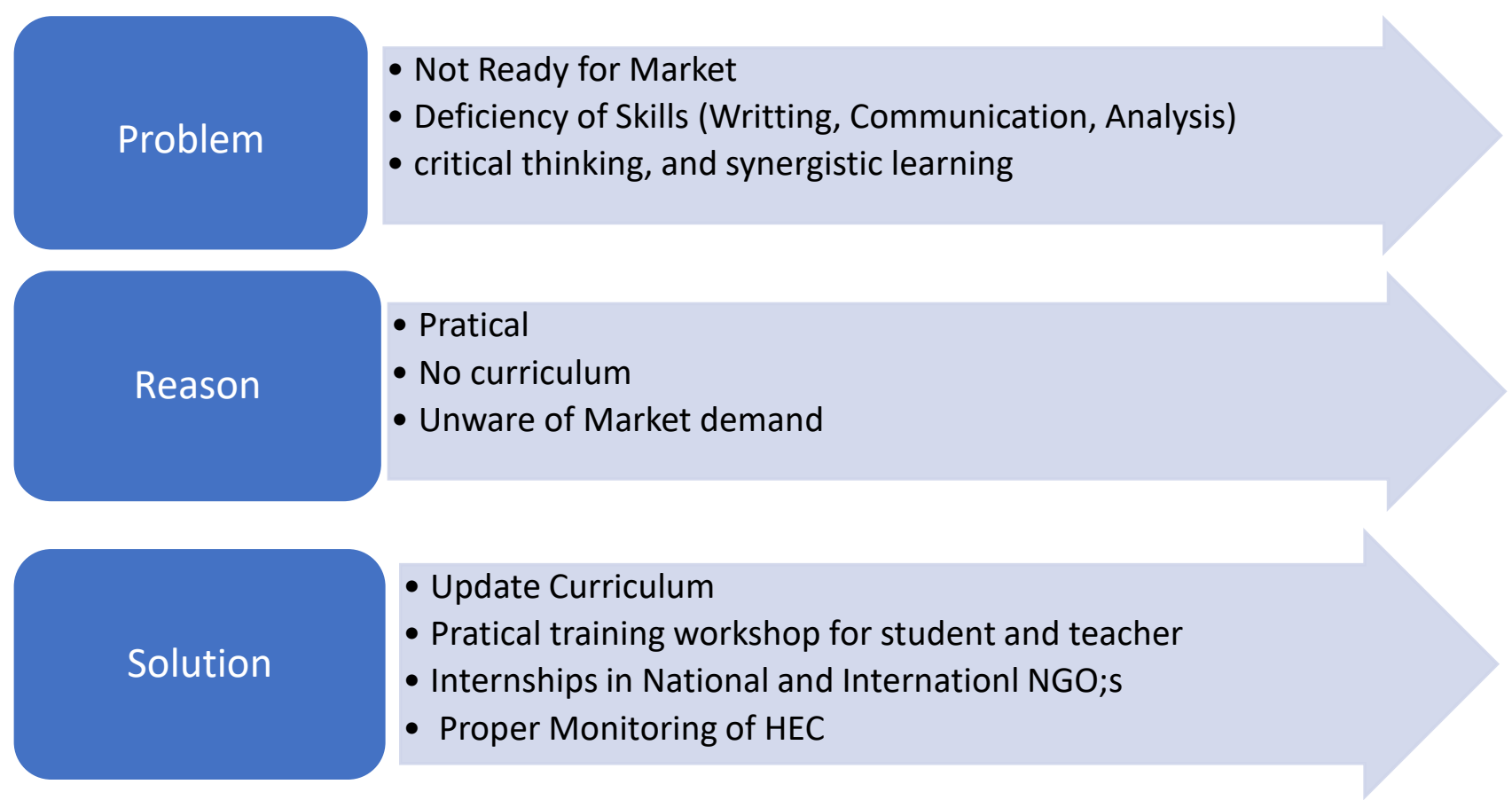

To meet this objective, there is a requirement for joint interest of colleges and businesses in the change of project directors from scholarly to rehearse. There is likewise a requirement for joint investment in instructive arranging. By doing this, there is certainty that the instructive framework is structured such that fulfils the regularly changing needs of the business. The model likewise shows the significance of focusing on both substance and the way toward instructing and creating project directors. Instructive methodologies should empower students to choose proper mixes of knowledge, practice and practices that will support and encourage nonstop change, inventive and basic reflection, adapting to vulnerability and complexities, expanding self-knowledge and the capacity to manufacture and add to superior groups. There is a basic requirement for greater interest in ceaseless project management preparing and advancement. The profundity and expansiveness of preparing and advancement isn't something that can be cultivated in a couple of courses. It requires a more extended responsibility and an undeniably increasingly multifaceted and methodical methodology both in the substance and procedure of instruction. For instance, solid instructing and ceaseless mentorship projects are basic to accomplishing this objective. Collaboration among colleges and ventures gives a solid establishment to both management advancement and ability combination. 


\section{Conclusion}

The paper analyses the experiences of project management professionals (university graduates) regarding project management education in universities of Pakistan. The perceptions are sought in the form of conducting 50 interviews with professionals working in different sectors related to the field of project management. The focus was to know the problems in Project Management education and its possible solutions. While using thematic analysis, the paper highlight three major problems faced by project management professionals while entering the labor market; deficiency in skills, gap between theory and practice, writing and M\&E. The interviewees suggested different solutions for different stakeholders, including university administration and HEC to improve the standard of project management education in Pakistan. Some of the suggestions for improvement are: revision of curriculum, practical assignments for students, the introduction of new syllabus of project management, training and workshop for teachers and students, and tight supervision from HEC of Pakistan on the universities.

In accordance with different analysts in the field of management education, we present the possibility that educational establishments ought to move away from the conveyance of standard bundle arrangements and strategy orientated instructional method to "learning and improvement which encourages the advancement of intelligent experts who can learn, work and adjust successfully in complex venture conditions." (Winter et al., 2006).

\section{Limitations and Challenges}

There were a few limitations in this study. Some of the professionals that we talked to, to gather data didn't have any academic background of Project Management. They joined those organizations with a simple bachelor or master degrees and learnt by practically been part of different projects. So they could not clearly tell what were the reasons of the knowledge gap faced by professionals in the market regarding project management. Further, there was a difference in perception of professionals from engineering academics and professionals with business studies academics.

The senior professionals with project management academics were really hard to be accessed as they had their core project execution and decision making duties and responsibilities. Much time was spend in trying to get in contact to these senior professionals. In addition to this all these professionals were serving in projects that each had a different area, discipline and scope which had an effect on their perception, experience and opinion about project management priority needs.

\section{Suggestion for Future Work}

The key to success in Project work is more of the adaptability with the job demands and work environment which is only possible if one has an academic background that has prepared them for the practical project work requirements. So it's very important for all the concerned authorities, i.e. HEC and University authorities to update and modify the syllabus and teaching methods for the Project Management course. The future of public sector development work and corporate sector innovation and research will be more of project oriented. Even in academics updated techniques of teaching and learning are being introduced which is project-based learning, where students are given projects to be planned and conducted in nearly all disciplines.

Thus an updated effective syllabus for the project management course at universities and other training institutes will be helpful in improving learning by pupils and work processes in projects 
practically. Further, there is very limited work done on project specific areas and not Project management as a whole like planning, monitoring and controlling, monitoring and evaluation, third party monitoring, result based monitoring. Much research is needed to be done in these regarding both the academic and market gap minimization, but the effect and role in project success and project management success.

\section{References}

Arain, F. M., \& Tipu, S. A. A. (2009). Status of Project Management Education in Pakistan. Educational Research and Reviews, 4(4), 148-155.

Ashleigh, M., Ojiako, U., Chipulu, M., \& Wang, J. K. (2012). Critical learning themes in project management education: Implications for blended learning. International Journal of Project Management, 30(2), 153-161.

Atkinson, R. (2008). Excellence in teaching and learning project management. International Journal of Project Management, 3(26), 221-222.

Braun, V., \& Clarke, V. (2006). Using thematic analysis in psychology. Qualitative research in psychology, 3(2), 77-101.

Córdoba, J. R., \& Piki, A. (2012). Facilitating project management education through groups as systems. International Journal of Project Management, 30(1), 83-93.

Crawford, C. B. (2005). Effects of transformational leadership and organizational position on knowledge management. Journal of knowledge management.

Crawford, L. (2005). Senior management perceptions of project management competence. International journal of project management, 23(1), 7-16.

Crosby, P. (2012). Predictive indicators of success in science \& engineering projects-application to the SKA initiative (Doctoral dissertation, Curtin University).

Ferraro, J. (2012). Project management for non-project managers. Amacom.

Flyvbjerg, B., Bruzelius, N., \& Rothengatter, W. (2003). Megaprojects and risk: An anatomy of ambition. Cambridge University Press.

Gardiner, P. D. (2005). Project management: A strategic planning approach. Macmillan International Higher Education.

Hammoud, M. S. (2008). Assessing project success: Comparing integrated change management and change management (Vol. 69, No. 03).

Japan International Cooperation Agency (JICA). (2003). Country study for Japan"s Official Development Assistance to the Islamic Republic of Pakistan -Development toward a sustainable society: Medium and long term perspectives. Tokyo: Institute for International Cooperation, JICA.

Jergeas, G. (2008). Analysis of the front-end loading of Alberta mega oil sands projects. Project Management Journal, 39(4), 95-104.

Jergeas, G. F., \& Ruwanpura, J. (2010). Why cost and schedule overruns on mega oil sands projects?. Practice Periodical on Structural Design and Construction, 15(1), 40-43.

Johnson, J. (2009). Chaos summary. The Standish Group Report.

Kerzner, H. (2019). Using the project management maturity model: strategic planning for project management. John Wiley \& Sons.

Khan, N. U., Burton, B. M., \& Power, D. M. (2011). Managerial views about dividend policy in Pakistan. Managerial Finance.

Maguire, M., \& Delahunt, B. (2017). Doing a thematic analysis: A practical, step-by-step guide for learning and teaching scholars. AISHE-J: The All Ireland Journal of Teaching and Learning in Higher Education, 9(3).

MinhajUllah, M. H. S. (2018). Business Students Career Preference in Pakistan: A Case of Private and Public Universities in Peshawar. International Journal of Business Studies Review, 4(1), 13-23. 
Morris, P. W., \& Hough, G. H. (1987). The anatomy of major projects: A study of the reality of project management.

O’Sullivan, D., Rolstadås, A., \& Filos, E. (2011). Global education in manufacturing strategy. Journal of Intelligent Manufacturing, 22(5), 663-674.

Thomas, J., \& Mengel, T. (2008). Preparing project managers to deal with complexity-Advanced project management education. International journal of project management, 26(3), 304-315.

Pomfret, D. T. (2008). Leadership in the project environment: A correlational study of leadership practices and project performance. ProQuest.

Reif, H. L., \& Mitri, M. (2005). How university professors teach project management for information systems. Communications of the ACM, 48(8), 134-136.

Sahibzada, S. A., Mahmood, M. A., \& Qureshi, S. K. (1992). Why Most Development Projects Fail in Pakistan? A Plausible Explanation [with Comments]. The Pakistan Development Review, 31(4), 1111-1122.

Stanley, R., \& Uden, L. (2013). Why projects fail, from the perspective of service science. In 7 th international conference on knowledge management in organizations: service and cloud computing (pp. 421-429). Springer, Berlin, Heidelberg.

Standish Group. Chaos reports. <http://www.standishgroup.com/sample_research/index.php>; 1994, 2004 [retrieved 25.02.2007].

Tabernik, T. J. (2008). Project management skills in the healthcare environment: Perceived importance to healthcare project success. Capella University.

Thomas, J., Mengel, T., \& Andres, N. (2004). Surfing on the edge of chaos-developing the master project manager. In PMI global conference.

Thomas, J., \& Mengel, T. (2008). Preparing project managers to deal with complexity-Advanced project management education. International journal of project management, 26(3), 304-315.

Ullah, M., \& Khan, N. U. (2018). Perception of University Graduates about Accounting Education in Pakistan. The Journal of Humanities and Social Sciences, 26(2), 31.

Winter, M., Smith, C., Morris, P., \& Cicmil, S. (2006). Directions for future research in project management: The main findings of a UK government-funded research network. International journal of project management, 24(8), 638-649.

World Bank. (2001, March). Pakistan's reform programme: Progress and prospects report. Retrieved January 25, 2004, from http://Inweb18.worldb ank.org/sar/sa.nsf/o83c4661ad49652f852567d7005d85b8/c3e79a8d2720625385256ao90o74d9 43?OpenDocument

World Bank. (2006). Pakistan: An evaluation of the World Bank's assistance. Washington: IEG, the World Bank. Retrieved December 2006,from http://Inweb18.worldbank.org/OED/OEDDocLib.nsf/DocUNIDViewForJavaSearch/8 F4238DA5D1176885257122006C11DC/\$file/pakistan_cae.pdf 